\title{
EFEITO DE ACARICIDAS SOBRE SCHIZOTETRANYCHUS HINDUSTANICUS (HIRST) (ACARI: TETRANYCHIDAE) E ÁCAROS PREDADORES EM CITROS NO ESTADO DE RORAIMA, BRASIL
}

\author{
A.L. Marsaro Júnior ${ }^{1}$, M.E. Sato ${ }^{2 *}$, R.M. de Aguiar ${ }^{3}$, \\ G.B. Vieira ${ }^{3}$, R.J. da Silva Júnior ${ }^{4}$ J.L.de C. Mineiro ${ }^{2 * *}$
}

${ }^{1}$ Embrapa Trigo, CP 451, CEP 99001-970, Passo Fundo, RS, Brasil, E-mail: alberto@cnpt.embrapa.br

\author{
RESUMO
}

\begin{abstract}
O ácaro-hindustânico-dos-citros, Schizotetranychus hindustanicus (Hirst), é uma praga de importância quarentenária, recentemente introduzida no Brasil. Até a condução do presente estudo, não havia informações na literatura sobre a eficiência de acaricidas no controle de $S$. hindustanicus, em condições de campo. O estudo teve por objetivo avaliar o efeito de alguns acaricidas, utilizados em pomares de citros no país, sobre o ácaro-praga e ácaros predadores (Phytoseiidae) presentes na cultura. O experimento foi conduzido em um pomar de citros (limão-tahiti), em Boa Vista, RR. Os acaricidas testados e respectivas concentrações (g i.a./100 L de água) foram: mancozebe (200), abamectina (0,36), espirodiclofeno (6), enxofre (400) e dimetoato (80). A aplicação foi realizada com equipamento acoplado a um trator, provido de pistolas, aplicando-se 10 litros de calda por planta. O delineamento estatístico foi inteiramente casualizado com seis tratamentos e cinco repetições. As avaliações foram realizadas aos 1, 4, 7, 14, 28, 42 e 56 dias após a aplicação (DAA). Em cada avaliação, foram coletados 20 folhas e 10 frutos por parcela, contando-se o número de ácaros $S$. hindustanicus e fitoseídeos. Todos os produtos reduziram significativamente a população do ácaro-hindustânico nas folhas até 28 DAA. Os acaricidas dimetoato e espirodiclofeno foram altamente eficientes no controle de $S$. hindustanicus, sendo que o espirodiclofeno apresentou um período de controle mais longo que dimetoato. Com relação aos ácaros predadores, dimetoato, enxofre e abamectina causaram mortalidades significativas (72 a 100\%) aos fitoseídeos, até 4 DAA. A espécie predominante de fitoseídeo foi Euseius concordis (Chant), correspondendo a $71 \%$ dos ácaros observados.
\end{abstract}

PALAVRAS-CHAVE: Ácaro-hindustânico-dos-citros, limão-tahiti, controlequímico, Phytoseiidae.

\begin{abstract}
EFFECT OF ACARICIDES ON SCHIZOTETRANYCHUS HINDUSTANICUS (HIRST) (ACARI: TETRANYCHIDAE) AND PREDACEOUS MITES ON CITRUS IN THE STATE OF RORAIMA, BRAZIL. Schizotetranychus hindustanicus (Hirst) is a pest of quarantine importance, recently introduced in Brazil. There was no information in the literature, on the efficacy of acaricides for the control of S. hindustanicus (Hirst) under field conditions, up to the conduction of this research. The objective of this study was to evaluate some acaricides currently used in citrus orchards, determining their effect on pest mites and predaceous mites (Phytoseiidae) living among the crop. The experiment was carried out in a citrus orchard (Tahitian lime), in the Boa Vista municipality, in the state of Roraima, Brazil. The acaricides studied and their respective concentrations (g a.i./100 1 of water) were: mancozeb (200), abamectin (0.36), spirodiclofen (6), sulphur (400) and dimethoate (80). The application was made using tractor-mounted hydraulic handgun sprayers, using a volume of $10 \mathrm{~L}$ of acaricide suspension per plant. The statistical design was a completely randomized design with six treatments and five replicates. The evaluations of the effect of chemicals on the populations of S. hindustanicus and predaceous mites (Phytoseiidae) were carried out at 1, 4, 7, 14, 28, 42 and 56 days after treatment (DAT). During each evaluation, 20 leaves and 10 fruits were collected per plot, counting the number of $S$. hindustanicus and phytoseiid mites. All the chemicals reduced significantly the population of hindustan citrus mite on the leaves until 28 DAT. The acaricides dimethoate and
\end{abstract}

${ }^{2}$ Instituto Biológico, Centro Experimental Central, Campinas, SP, Brasil.

${ }^{3}$ FARES, Boa Vista, RR, Brasil.

${ }^{4}$ Embrapa Roraima, Boa Vista, RR, Brasil.

*Bolsista de Produtividade em Pesquisa CNPq.

**Bolsista de Pós-Doutorado do CNPq.

Arq. Inst. Biol., São Paulo, v.79, n.1, p.75-83, jan./mar., 2012 
spirodiclofen were highly effective against $S$. hindustanicus, and spirodiclofen presented a longer effective period than dimethoate. Regarding the predaceous mites, dimethoate, sulfur and abamectin caused significant mortality (72 to $100 \%$ ) to the predators up to 4 DAT. The predominant species of Phytoseiid mite was Euseius concordis (Chant), corresponding to $71 \%$ of mites of this family.

KEY WORDS: Citrus hindu mite, Tahitian lime, chemical control, Phytoseiidae.

\section{INTRODUÇÃO}

O Ministério da Agricultura, Pecuária e Abastecimento (MAPA) enviou em julho de 2008 à Secretaria de Agricultura, Pecuária e Abastecimento (SEAPA/ RR) a notificação sobre a detecção da praga exótica Schizotetranychushindustanicus (Hirst) (Acari: Tetranychidae) em citros em Roraima (PÁGINA RuRAL, 2008).

$\mathrm{O}$ ácaro $S$. hindustanicus, também conhecido como ácaro-hindustânico-dos-citros, foi detectado inicialmente em folhas e frutos de limão-tahiti e galeguinho, no Município de Boa Vista, RR. No Brasil, esse ácaro foi identificado pela primeira vez pela Dra. Denise Navia, da Embrapa Recursos Genéticos e Biotecnologia, sendo sua identificação confirmada pelo Dr. Carlos Holger Wenzel Flechtmann, da Escola Superior de Agricultura "Luiz deQueiroz" (ESALQ/ USP) (PÁgina RuRal, 2008; Navia et al., 2008; NAVIA; MARSARO JUNIOR, 2010).

Ácaros da espécie S. hindustanicus foram relatados pela primeira vez no Sul da Índia (Coimbatore) em 1924. Esse ácaro foi encontrado em 2002 em Zulia no Oeste da Venezuela. Até o início de 2008, não havia informações sobre a ocorrência do ácaro em outros países da América Latina (INRA, 2008; NAVIA et al., 2008).

Provavelmente, esse ácaro foi introduzido em Roraima de material proveniente da Venezuela (Página Rural, 2008). As maiores infestações do ácaro exótico têm sido observadas no Município de Boa Vista, RR.

Os danos observados em citros consistem em manchas esbranquiçadas sobre folhas e frutos, que variam de 1 a $2 \mathrm{~mm}$, distribuídas uniformemente, ocupando todo o tecido infestado, o que lhes dá um aspecto peculiar. Toda a copa pode apresentar sintomas. Cobrindo as manchas esbranquiçadas pode se observar uma fina teia sob a qual há ovos, ácaros adultos e imaturos (NAviA et al., 2008). Embora não se tenha estudos quantificando os prejuízos causados pela praga, ela deve afetar significativamente o valor comercial dos frutos para venda "in natura" e, em altas infestações, reduzir a taxa fotossintética das plantas e, consequentemente, a produção.

Devido à introdução recente do ácaro-hindustânico-dos-citros no Brasil, praticamente não se têm informações sobre métodos de controle desse ácaropraga ou inimigos naturais a ele associado.

Dentre os principais inimigos naturais de ácaros fitófagos, destacam-seosácarosdafamíliaPhytoseiidae, que se mostram efetivos no controle biológico de muitas espécies de ácaros-praga (MORAES, 1991). De um total deaproximadamente2.250 espécies deácaros fitoseídeos catalogados em todo o mundo, mais de 200 espécies foram registradas para citros (MORAES et al., 2004). Dos fitoseídeos reportados para a cultura, mais de dez espécies são encontradas no Brasil (MorAEs et al., 2004). SATO et al. (1994a) observaram a presença de seis espécies de ácaros predadores da família Phytoseiidae em pomar de laranja em Presidente Prudente, SP, sendo que as espécies de maior incidência foram Iphiseiodes zuluagai Denmark \& Muma, Euseius citrifolius Denmark \& Muma e Euseius concordis (Chant), representando 47,3; 26,5 e 25,7\% dos ácaros coletados, respectivamente.

AfamíliaStigmaeidae também apresenta espécies de ácaros predadores que se alimentam de ácarospraga em citros, podendo-se citar os dos gêneros Agistemus e Zetzellia. Em um estudo realizado no Estado de São Paulo, verificou-se que a espécie de estigmeídeo mais frequente foi Agistemus brasiliensis Matioli, Ueckermann \& Oliveira $(80 \%)$, seguida de Agistemus floridanus Gonzalez (15\%) e Zetzellia malvinae Matioli, Ueckermann \& Oliveira (5\%) (MAtioli, 2002).

Um dos sérios problemas associados ao controle químico deácaros-praga em citroséa alta mortalidade provocada pelos pesticidas agrícolas aos ácaros predadores e outros inimigos naturais presentes na cultura. Devidoà importância do problema, diversos trabalhos têm sido realizados para avaliar a toxicidade e/ou a seletividade de agroquímicos a ácaros predadores da família Phytoseiidae presentes em citros no Brasil (Komatsu; NAKANO, 1988; SATO et al., 1994b; SATO et al., 1995; SATO et al., 1996; YАМАМОTO et al., 1995; REIS et al., 1998; ReIs et al., 2005; YАмAMOTO; BESSANEZI, 2003). Recentemente, alguns trabalhos também têmenfocado a seletividade de pesticidas aos ácaros predadores da família Stigmaeidae (SILVA et al., 2009).

O objetivo do presente trabalho foi avaliar o efeito de alguns acaricidas utilizados em citros no Brasil, sobre o ácaro-praga $S$. hidustanicus e ácaros predadores (Phytoseiidae) presentes em pomar de citros em Boa Vista, RR.

\section{MATERIAL E MÉTODOS}

O experimento foi conduzido no Município de Boa Vista, RR, N $02^{\circ} 53^{\prime} 45^{\prime \prime}$ e O $60^{\circ} 40^{\prime} 33^{\prime \prime}$, no período 
de11/3/2009 a 2/5/2009, em pomar de limão-tahiti, Citrus latifolia Tanaka, de seis anos de idade, em espaçamento de $7 \mathrm{~m}$ entre ruas e $5 \mathrm{~m}$ entre plantas. A altura das plantas era de, aproximadamente, $3 \mathrm{~m}$.

O delineamento estatístico adotado foi o inteiramente casualizado, com seis tratamentos e cinco repetições. Os produtos e as concentrações utilizadas são apresentados na Tabela 1.

Cada parcela constou de cinco plantas de limão, sendo avaliadas as três plantas centrais. As parcelas foram distribuídas no campo de forma que, entre as linhas com plantas tratadas, foi deixada uma linha de plantas sem aplicação de acaricidas.

A aplicação foi realizada em 12/3/2009, utilizando-se um equipamento acoplado a um trator, provido de pistolas. $\mathrm{O}$ volume de calda aplicado em cada planta foi de, aproximadamente, $10 \mathrm{~L}$. Uma avaliação prévia foi efetuada em 11/3/2009 e as demais avaliações foram realizadas aos 1, 4, 7, 14, 28, 42 e 56 dias após a aplicação (DAA).

Em cada avaliação, foram coletados 20 folhas e 10 frutos na parte útil de cada parcela (três plantas centrais). No caso de frutos, as coletas foram feitas até os 28 dias após a aplicação. Após esse período, o número de frutos de tamanho adequado $(\geq 3 \mathrm{~cm}$ de diâmetro) em cada parcela tornou-se insuficiente na maioria das parcelas a serem avaliadas.

As folhas e os frutos de cada parcela foram colocados separadamente em sacos de papel, no interior de caixas de poliestireno expandido (Isopor ${ }^{\circledR}$ ) contendo gelo, para diminuir a atividade dos ácaros, e transportados para o laboratório (setor de Entomologia da Embrapa Roraima). A avaliação do número deácaros S. hindustanicus (formas ativas e ovos) e fitoseídeos (formas ativas) foi feita utilizando-se microscópio estereoscópico, com aumento de até 50 vezes.

Amostras do ácaro-praga e inimigos naturais foram colocadas em frascos de vidro contendoálcool $70 \%$ e encaminhadas ao Laboratório de Acarologia, do Instituto Biológico, em Campinas, SP, para identificação específica.

Os dados do número de ácaros $S$. hindustanicus e fitoseídeos foram transformados em $\sqrt{x+05}$, visando homogeneidade da variância (homocedasticidade) e distribuição normal, e analisados pelo teste F. As médias foram comparadas pelo teste de Tukey a 5\% de significância, utilizando-se o programa Bioestat 3.0 (AYres et al., 2003).

\section{RESULTADOS E DISCUSSÃO}

Efeito dos acaricidas sobre o ácaro-hindustânico-dos-citros nas folhas. A avaliação do número de ácaros $S$. hindustanicus em folhas indicou que todos os produtos testados reduziram significativamente $(\mathrm{F} \geq 22,15 ; \mathrm{G} . \mathrm{L} .=5,24 ; P \leq 0,0001)$ a população do ácaro-hindustânico-dos-citros em folhas até 28 DAA, no entanto, somente espirodiclofeno e dimetoato apresentaram altas eficiências de controle $(\geq 99,4 \%)$ nessa avaliação. A partir de 42 DAA, somente espirodiclofeno apresentou controle efetivo da praga, com $97,6 \%$ de redução populacional aos 42 DAA, e $84,8 \%$ de redução aos 56 DAA (Tabela 2).

O produto mancozebe não chegou a apresentar altas eficiências de controle em nenhuma das avaliações realizadas. $\mathrm{O}$ mais alto índice de redução populacional foi de $77,5 \%$, aos 4 DAA. Nas demais avaliações, as porcentagens de redução populacional foram iguais ou inferiores a $57,3 \%$.

Abamectina, em mistura com óleo (Aureo ${ }^{\circledR}$ ) a 0,25\%, mostrou-se efetivo no controle do ácarohindustânico-dos-citros apenas nas avaliações realizadas aos 1 e 7 DAA, com porcentagens de redução populacional entre 84,7 e $93,9 \%$. A partir de 14 DAA, as porcentagens de redução populacional foram iguais ou inferiores a $72,5 \%$.

O enxofre foi eficiente até 14 DAA, com porcentagens de redução populacional entre 88,9 e $94,1 \%$. Após essa avaliação, as porcentagens de controle foram inferiores a $70 \%$, chegando a $0 \%$, aos 56 DAA.

Os dois melhores acaricidas foram dimetoato e espirodiclofeno, que chegaram a apresentar $100 \%$ de controle do ácaro-hindustânico-dos-citros, em algumas avaliações.

Oespirodiclofeno apresentou controle efetivo do ácaro-hindustânico-dos-citros por um período maior que o dimetoato, com porcentagens de redução populacional entre 97,5 e 100\%, nas avaliações realizadas entre o quarto e o 42 DAA.

O dimetoato apresentou eficiências de controle entre 99,4 e $100 \%$ até 28 DAA, e nas duas últimas avaliações (42 e 56 DAA), as porcentagens de redução populacional foram iguais ou inferiores a $70,9 \%$.

Tabela 1 - Tratamentos empregados no experimento de controle de Schizotetranychus hindustanicus em citros. Boa Vista, RR.

\begin{tabular}{llccc}
\hline Tratamentos & Produto comercial & Formulação & g IA/100 L de água & mL ou g PC/100 L de água \\
\hline Testemunha & - & - & - & - \\
mancozebe & Dithane NT & WP & 200 & $250 \mathrm{~g}^{*}$ \\
abamectina & Abamex & EC & 0,36 & $20 \mathrm{~mL}^{*}$ \\
espirodiclofeno & Envidor & SC & 6 & $25 \mathrm{~mL}$ \\
enxofre & Kumulus DF & EC & 400 & $500 \mathrm{~g}$ \\
dimetoato & Agritoato 400 & 80 & $200 \mathrm{~mL}$ \\
\hline
\end{tabular}

*acaricida Abamex $+0,25 \%$ de óleo Aureo ${ }^{\circledR}$ (Éster metílico de óleo de soja). 

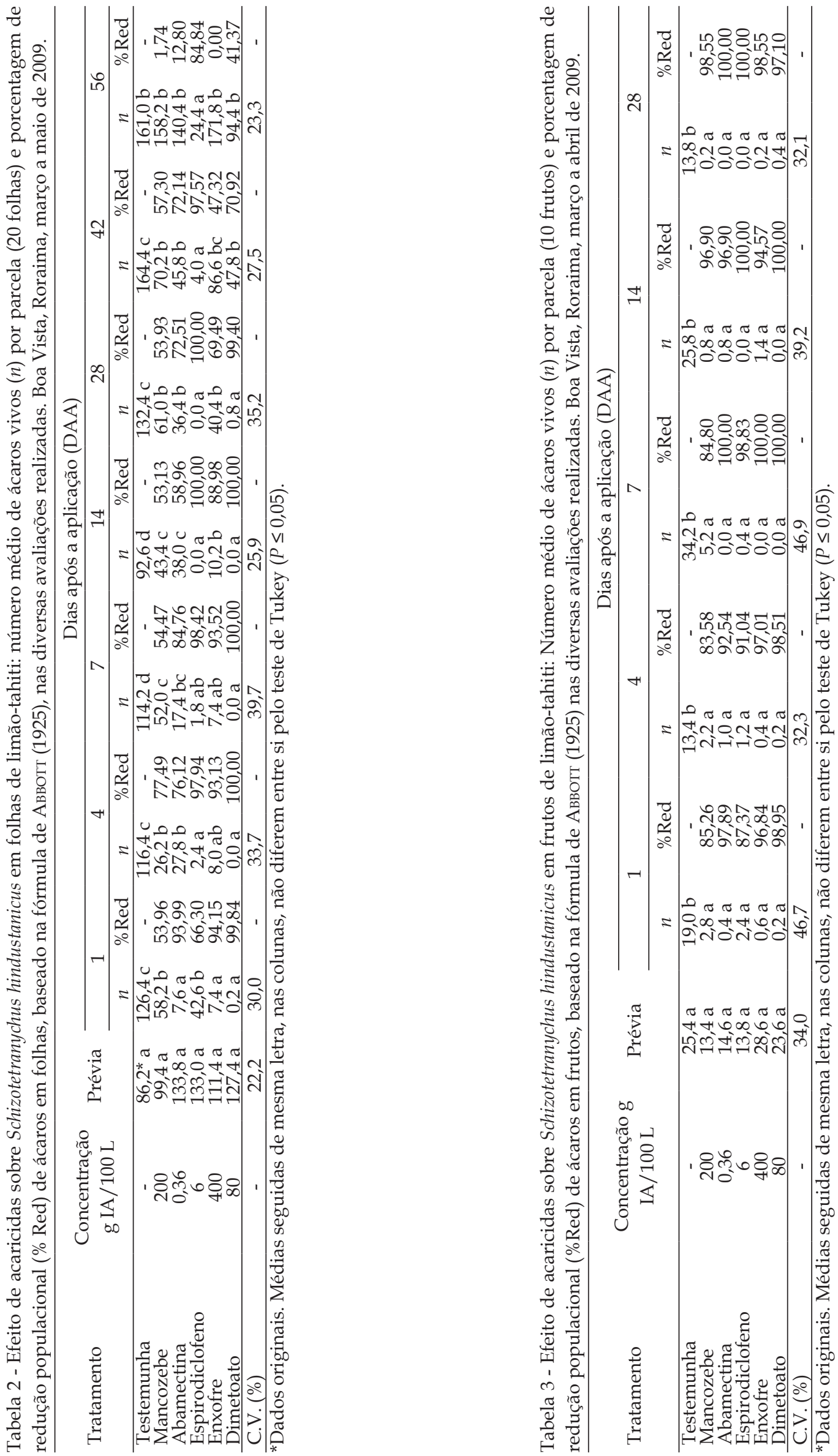
Espirodiclofeno apresentou eficiência de controle relativamente baixa $(66,3 \%)$ na avaliação realizada no primeiro dia após a aplicação, devido à sua menor eficiência sobre adultos de ácaros. Esse produto tem ação principalmente sobre ovos e imaturos (larvas e ninfas), com alta eficiência sobre ovos e larvas. $\mathrm{O}$ produto também afeta significativamente a fecundidade e a fertilidade das fêmeas tratadas (MARCic, 2007). O principal mecanismo de ação do produto é a redução na biossíntese de lipídeos (VAN PotTeLBERGE et al., 2009).

No caso de dimetoato, o acaricida atua como inibidor de acetilcolinesterase, que é responsável pela hidrólise de acetilcolina nas fendas sinápticas do sistema nervoso. Os organofosforados (grupo químico do dimetoato) normalmente matam rapidamente as pragas por hiperexcitação (RAGA; SATO, 2006). Esse fato pode explicar a alta eficiência do produto, mesmo a 1 DAA.

Embora dimetoato tenha se mostrado altamente eficiente contra o ácaro-hindustânico-dos-citros, esse acaricida não tem se mostrado efetivo no controle de diversas espécies de ácaros-praga, tais como Tetranychus urticae (Koch) (SATO et al., 2000; Alzoubi; Cobanogu, 2008) e Tetranychus cinnabarinus (Boisd.) (DeEP; Dhooria, 2004). O mau desempenho de dimetoato está provavelmente associado ao desenvolvimento de resistência dos ácaros dessas espécies ao acaricida.

Apesar de ter sido realizada a contagem dos ovos de S. hindustanicus presentes nas folhas, existe certa dificuldade de interpretação dos resultados, devido à impossibilidade de saber se os ovos estavam viáveis ou não (durante as avaliações), pela metodologia utilizada (visualização em microscópio estereoscópico) (Fig. 1). No caso de espirodiclofeno, os ovos encontrados nas folhas (ou frutos) poderiam ser inviáveis, devido ao efeito altamente tóxico do produto sobre essa fase de desenvolvimento (PREE et al., 2005; ReIs et al., 2005; MARCIC, 2007).
Os resultados indicam redução significativa no número de ovos ( $\mathrm{F} \geq 12,97$; G.L. $=5,24 ; P \leq 0,0001)$ doácaro-hindustânico-dos-citros em folhas delimão, entre 14 e 28 DAA, para todos os produtos, com exceção de mancozebe (com diferença significativa apenas aos 14 DAA) (Fig. 1).

Os menores números de ovos em folhas foram observados para os tratamentos com espirodiclofeno e dimetoato. A porcentagem de redução no número de ovos chegou a $97,0 \%$ aos 14 DAA para dimetoato, e a $97,5 \%$, aos 42 DAA para espirodiclofeno. No caso de espirodiclofeno, reduções significativas no número de ovos em folhas foram observadas até 56 DAA (F $\geq 10,73$; G.L. $=5,24 ; P=0,0001$ ) (Fig. 1).

Efeito dos acaricidas sobre oácaro-hindustânicodos-citros nos frutos. Com relação às avaliações de ácaros em frutos, observou-se queo número deácaros em frutos foi bem inferior que em folhas, sendo de aproximadamente 1,99 ácaros por fruto. O número de ácaros por folha foi quase três vezes maior ao número deácaros por fruto, considerando-se apenas a avaliação prévia. Esse resultado indica uma nítida preferência do ácaro-hindustânico-dos-citros por folhas, em relação a frutos (Tabela 3 ).

Devido ao número relativamente baixo de ácaros em frutos, torna-se difícil a interpretação dos resultados, visando à comparação da eficiência de controle dos diferentes produtos, utilizando-se o número de ácaros por fruto como parâmetro. $\mathrm{O}$ número médio de ácaros em frutos (19,91 ácaros), por parcela na avaliação prévia, foi 5,8 vezes menor do que o de ácaros em folhas por parcela na mesma avaliação.

Considerando-se apenas o número de ácaros em frutos, todos os tratamentos apresentaram redução populacional significativa deácaros $S$. hindustanicus, até 28 DAA ( $\mathrm{F} \geq 12,71 ; \mathrm{G} . \mathrm{L} .=5,24 ; P \leq 0,0001)$. Não foram observadas diferenças significativas entre os tratamentos com aplicação de acaricidas, diferindo apenas da testemunha.

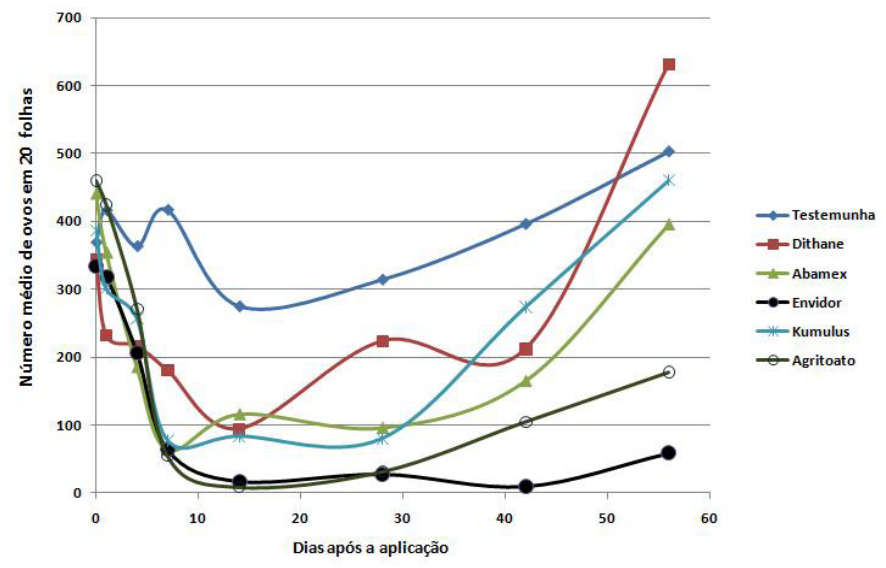

Fig. 1 - Variação do número de ovos de Schizotetranychus hindustanicus em folhas de limão-tahiti, para diferentes tratamentos com acaricidas. Boa Vista, Roraima, março a maio de 2009. 


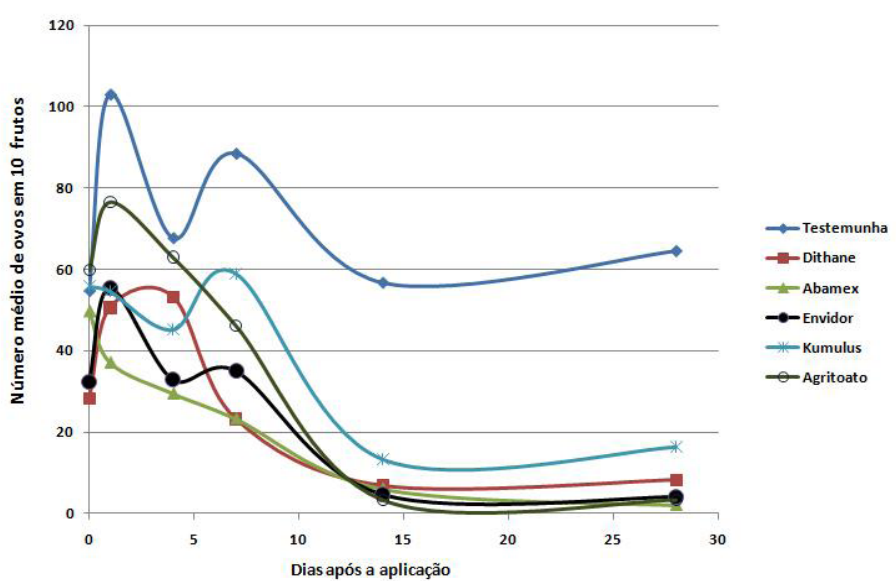

Fig. 2 - Variação do número de ovos de Schizotetranychus hindustanicus em frutos de limão-tahiti, para diferentes tratamentos com acaricidas. Boa Vista, Roraima, março a abril de 2009.

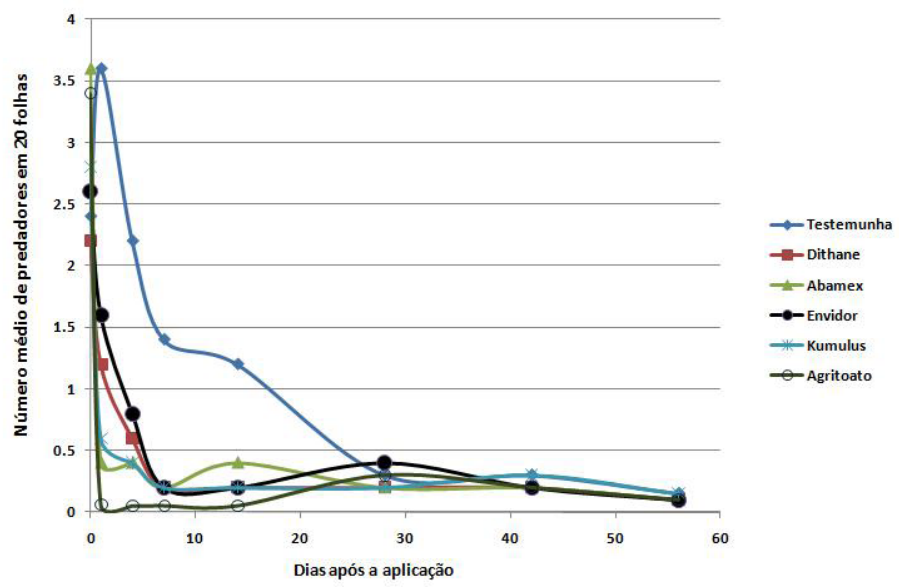

Fig. 3 - Variação do número de ácaros fitoseídeos em folhas de limão-tahiti, para diferentes tratamentos com acaricidas. Boa Vista, Roraima, março a maio de 2009.

Em termos numéricos, os melhores resultados foram observados para abamectina, dimetoato e espirodiclofeno, que chegaram a causar $100 \%$ de controle dos ácaros em mais de uma avaliação, e proporcionaram reduções populacionais entre 96,9 e $100 \%$, nas avaliações de 7, 14 e 28 DAA.

O número médio de ovos por fruto $(4,67$ ovos $)$ fruto) também foi bem inferior ao número de ovos por folha, com um valor 4,2 vezes menor, na avaliação prévia (Fig. 2).

Nas primeiras avaliações (1 a 7 DAA), o número de ovos foi semelhante nos diferentes tratamentos, pelo fato da maioria dos ovos ainda permanecerem túrgidos nos frutos, mesmo após a aplicação. Por esse motivo, os ovos inviáveis também estão incluídos nessas contagens iniciais.

Todos os tratamentos com acaricidas diferiram significativamente $(\mathrm{F} \geq 45,44 ; \mathrm{G} . \mathrm{L} .=5,24 ; P \leq 0,0001)$ da testemunha, nas avaliações realizadas entre $14 \mathrm{e}$ 28 DAA. Os melhores resultados foram observados para abamectina, espirodiclofeno e dimetoato, que diferiram significativamente de enxofre e da testemunha, nas duas últimas avaliações. Para esses três acaricidas, as porcentagens de redução no número de ovos foram iguais ou acima de $93,8 \%$, e o número médio de ovos remanescentes por fruto foi inferior 0,5 (entre 0,2 e 0,4 ovos/fruto), na última avaliação realizada para esse parâmetro aos 28 DAA.

Espirodiclofeno tem sidoutilizado para o controle de outras espécies deácaros-praga [Brevipalpus phoenicis (Geijskes), Phyllocoptruta oleivora (Ashmead), Panonychus citri (McGregor), Polyphagotarsonemus latus (Banks)] em citros (Agrofit, 2010), podendo ser uma boa alternativa para o controle do ácarohindustânico-dos-citros em Roraima.

Dimetoato também tem sido empregado para o controle de diversos insetos [Lepidosaphes beckii (Newman), Chrysomphalus ficus Ashmead, Anastrephafraterculus (Wiedemann), Aleurothrixus floccosus (Maskell), Praelongorthezia praelonga Douglas, Toxoptera citricida (Kirkaldy)] e ácaros (P. oleivora) em citros no Brasil (Agrofit, 2010), 
podendo auxiliar no controle de S. hindustanicus em citros no País.

Outros acaricidas como abamectina e enxofre também podem contribuir para a redução populacional do ácaro-hindustânico-dos-citros, quando aplicados em citros em Roraima.

Vale ressaltar que os acaricidas avaliados neste trabalho somente poderão ser utilizados em condições de campo para o controle de S. hindustanicus quando eles estiverem registrados no MAPA para o controle desse ácaro na cultura dos citros.

Efeito dos acaricidas sobre ácaros predadores. O baixo número de ácaros predadores em folhas e frutos dificultou a interpretação dos resultados sobre o efeito dos acaricidas sobre esses inimigos naturais (Fig. 3). O número total de ácaros em frutos foi muito baixo (< 5 espécimes, na avaliação prévia) não permitindo o uso dos dados nesse trabalho. Praticamente a totalidade dos fitoseídeos foi observada em folhas.

A espécie predominante de fitoseídeo foi $E$. concordis, correspondendo a aproximadamente $71 \%$ dosácaros observados dessa família. Outras espécies observadas foram Galendromus annectens (DeLeon) (15\%) e I. zuluagai (14\%).

Dimetoato, enxofre e abamectin causaram mortalidades significativas ( $\mathrm{F} \geq 3,40 ;$ G.L. $=5,24 ; P \leq$ $0,02)$ aos fitoseídeos, até 4 DAA. As mortalidades para enxofre e abamectina variaram entre 81 a $88 \%$ nesse período, enquanto que para dimetoato, as mortalidades foram de 100\% (Fig. 3).

Resultados semelhantes foram obtidos por SATO et al. (1995), que verificaram que o enxofre causou mortalidade inicial elevada aos fitoseídeos (ao redor de $80 \%$ ), principalmente na primeira semana após a aplicação. No caso de abamectina, SATO et al. (1996) observaram que o acaricida causou mortalidade significativa aos fitoseídeos (I. zuluagai), com reduções populacionais entre 60 e $70 \%$, no primeiro dia após a aplicação. YAMAMOTO; BASSANEZI (2003) reportaram que dimetoato foi nocivo às principais espécies de ácaros fitoseídeos presentes em citros.

Os demais produtos (mancozebe e espirodiclofeno) causaram mortalidades entre 45 e $63 \%$ nos primeiros quatro dias após o tratamento, mas não diferiram significativamente da testemunha (Fig.3).

Os resultados se assemelham com os obtidos por ReIs et al. (2005), que avaliaram a mortalidade e a reprodução de fêmeas adultas de ácaros predadores após o contato residual com espirodiclofeno e concluíram que o acaricida apresentava algum efeito prejudicial a esses inimigos naturais, classificando o produto como levemente nocivo (classe 2) para o fitoseídeo E. citrifolius.

A partir de 7 DAA, já não foram observadas diferenças estatísticas $(P \geq 0,05)$ entre os tratamentos, provavelmente devido à baixa população de predadores após essa data (Fig. 3).
São diversas as possíveis explicações para a baixa população de ácaros fitoseídeos, principalmente a partir da terceira semana do experimento, podendose mencionar condições climáticas desfavoráveis aos fitoseídeos nesse período, presença de poucas presas (ou alimentos alternativos) favoráveis à multiplicação dos predadores, efeito de outros organismos (artrópodes predadores e entomopatógenos) sobre esses inimigos naturais (CLEMENTS; HARMSEN, 1992; GERson et al., 2003; FerLA; MoraEs, 2003, MinEIRO et al., 2008).

Praticamente não há informações sobre a fauna de artrópodes (incluindo ácaros), as interações interespecíficas e as influências dos elementos meteorológicos sobreesses organismos em agroecossistema de citros (ex.: plantas de citros, plantas daninhas, vegetação ao redor dos pomares, solo) em Roraima, dificultando a discussão sobre o assunto.

Uma das possíveis interações entre espécies de ácaros em citros é a competição entre ácaros das famílias Stigmaeidae e Phytoseiidae (ClEMENTS; HARMSEN, 1992; SATo et al., 2001; Mineiroet al., 2008).Silva (2009) mencionou uma predação mútua de ovos por ácaros estigmeídeos (A.brasiliensis) e fitoseídeos, sendo que os ovos de fitoseídeos foram favoráveis à multiplicação dos estigmeídeos que se alimentaram deles. No entanto, ovos de estigmeídeos não se mostraram favoráveis à multiplicação dos fitoseídeos.

Embora em menor proporção (1/6) que os fitoseídeos, também foram observados ácaros predadores da família Stigmaeidae nesse pomar cítrico avaliado. Os ácaros predadores observados dessa família pertenciam ao gênero Agistemus e, devido à sua baixa população, não foram realizadas análises estatísticas.

Ácaros estigmeídeos, como os da espécie A. brasiliensis, mostram-se sensíveis à maioria dos acaricidas utilizados em citros. Segundo SiLva et al. (2009), espirodiclofeno foi altamente nocivo aos ácaros dessa espécie, comprometendo sua reprodução. Abamectina e dimetoato foram moderadamente nocivos, apresentando um efeito total (efeitos sobre mortalidade e reprodução) acima de $91 \%$. Essa alta sensibilidade dos estigmeídeos a produtos químicos pode ter influenciado na população desses predadores no pomar avaliado.

\section{CONCLUSÕES}

Todos os acaricidas reduziram significativamente a população do ácaro-hindustânico-dos-citros nas folhas até 28 dias após a aplicação.

Os acaricidas dimetoato e espirodiclofeno foram altamente eficientes no controle de S. hindustanicus, sendo que, espirodiclofeno apresentou um período de controle mais longo que dimetoato. 
Dimetoato, enxofre e abamectina causaram mortalidades aos ácaros predadores fitoseídeos, até quatro dias após a aplicação.

\section{AGRADECIMENTOS}

Os autores agradecem ao MAPA (Ministério da Agricultura, Pecuária e Abastecimento) por custear as viagens de Mário E. Sato, de Campinas, SP, a Boa Vista, RR, durante a realização do estudo. Aos técnicos da ADERR (Agência de Defesa Agropecuária do Estado de Roraima) pelo apoio na condução das atividades em campo. Ao CNPq pela bolsa de produtividade em pesquisa ao segundo autor.

\section{REFERÊNCIAS}

ABBOTT, W.S. A method for computing the effectiveness of an insecticide. Journal of Economic Entomology, v.18, p.265-267, 1925.

AGROFIT: Sistema de Agrotóxicos Fitossanitários, do Ministério da Agricultura, Pecuária e Abastecimento. Disponível em: <http:extranet.agricultura.gov.br/agrofit_cons/principal_agrofit_cons $>$. Acesso em: $20 \mathrm{fev}$. 2010.

ALZOUBI, S.; COBANOGU, S. Evaluation of the different control methods for the two-spotted spider mites by computer software and percentage efficacy. Journal of Economic Entomology, v.5, n.4, p.290-294, 2008.

AYRES, M.; AYRES JR., M.; AYRES, D.L.; SANTOS, A.S. dos Bio Estat 3.0. Aplicações estatísticas nas áreas das ciências biológicas e médicas. Belém: Sociedade Civil Mamirauá; Brasília: CNPq, 2003. 290p.

CLEMENTS, D.R.; HARMSEN, R. Stigmeid-phytoseiid interactions and the impact of natural enemy complexes on plant-inhabiting mites. Experimental and Applied Acarology, v.14, p.327-341, 1992.

DEEP, K.; DHOORIA, M.S. Relative efficacy of different pesticides against red spider mite, Tetranychus cinnabarinus (Boisd.) (Acari: Tetranychidae). Journal of Research, Punjab Agricultural University. Disponível em: <http://www.cababstractsplus.org/abstracts/ Abstract. aspx?AcNo= 20043104700> Acesso em:30 dez. 2004.

FERLA, N.J.; MORAES G.J. de. Oviposição dos ácaros predadores Agistemus floridanus Gonzalez, Euseius concordis (Chant) e Neoseiulus anonymus (Chant \& Baker) (Acari) em resposta a diferentes tipos de alimento. Revista Brasileira de Zoologia, v.20, p.153-155, 2003.

GERSON, U.; SMILEY, R.L.; OCHOA, R. Mites (Acari) for pest control. Oxford: Blackwell Science, 2003. $539 \mathrm{p}$.
INRA (Institut Scientifique de Recherche Agronomique). Spider Mites Web. Disponível em. <http:/ / www.ensam. inra.fr/CBGP/spmweb/notespecies.php?id=763>. Acesso em: 23 jul 2008.

KOMATSU, S.S.; NAKANO, O. Estudos visando o manejo do ácaro da leprose em citros através do ácaro predador Euseius concordis (Acari: Phytoseiidae). Laranja, v.9, p.125-146, 1988.

MARCIC, D. Sublethal effects of spirodiclofen on life history and life-table parameters of two-spotted spider mite (Tetranychus urticae). Experimental and Applied Acarology, v.42, n.2, p.121-129, 2007.

MATIOLI, A.L. Aspectos taxonômicos e bioecológicos de ácaros predadores Stigmaeidae (Acari) de ocorrência em citros. 2002. 82p. Tese (Doutorado em Agronomia Agrícola) - Faculdade de Ciências Agrárias e Veterinárias - Universidade Estadual Paulista, Jaboticabal, 2002.

MINEIRO, J.L. de C.; SATO, M.E.; RAGA, A.; ARTHUR, $\mathrm{V}$. Population dynamics of phytophagous and predaceous mites on coffee in Brazil, with emphasis on Brevipalpus phoenicis (Acari: Tenuipalpidae). Experimental and Applied Acarology, v.44, p.277-291, 2008.

MORAES, G.J. de. Controle biológico de ácaros fitófagos. Informe Agropecuário, v.15, n.167, p.56-62, 1991.

MORAES, G.J. de; McMURTRY, J.A.; DENMARK, H.A.; CAMPOS, C.B. A revised catalog of the mite family Phytoseiidae. Zootaxa, v.434, p.1-494, 2004.

NAVIA, D.; MARSARO JÚNIOR, A.L. First report of the citrus hindu mite, Schizotetranychus hindustanicus (Hirst) (Prostigmata: Tetranychidae), in Brazil. Neotropical Entomology, v.39, n.1, p.140-143, 2010.

NAVIA, D.; MARSARO JÚNIOR, A.L.; QUERINO, R.B.; FLECHTMANN, C.H.W. Danos ocasionados por ácaros tetraniquídeos do gênero Schizotetranychus aos citros no Estado de Roraima. In: CONGRESSO BRASILEIRO DE ENTOMOLOGIA, 22., Uberlândia, MG, 2008. Resumos. Uberlândia, 2008.

PÁGINA RURAL. RR: praga exótica dos citros é detectada no Estado. [Roraima] 2008. Disponível em: <http://www.paginarural.com.br/noticia/93794/praga-exotica-dos-citros-e-detectada-no-estado>. Acesso em: 22 jul. 2008

PREE, D.J.; WHITTY, K.J.; VAN DRIEL, L. Baseline susceptibility and cross resistances of some new acaricides in the European red mite, Panonychus ulmi. Experimental and Applied Acarology, v.37, p.165-171, 2005.

RAGA, A.; SATO, M.E. Time-mortality for fruit flies (Diptera: Tephritidae) exposed to insecticides in laboratory. Arquivos do Instituto Biológico, São Paulo, v.73, n.1, p.73-77, 2006. 
REIS, P.R.; CHIAVEGATO, L.G.; MORAES, G.J. de; ALVES, E.B.; SOUSA, E.O. Seletividade de agroquímicos ao ácaro predador Iphiseiodes zuluagai Denmark \& Muma (Acari: Phytoseiidae). Anais da Sociedade Entomológica do Brasil, v.27, n.2, p. 65-274, 1998.

REIS, P.R.; PEDRO NETO, M.; FRANCO, R.A. Controle de Brevipalpus phoenicis (Geijskes, 1939) e Oligonychus ilicis (McGregor, 1917) (Acari: Tenuipalpidae, Tetranychidae) em cafeeiro e o impacto sobre ácaros benéficos: II - Spirodiclofen e Azocyclotin. Ciência e Agrotecnologia, v.29, n.3, p.528-537, 2005.

SATO, M.E.; RAGA, A.; CERÁVOLO, L.C.; ROSSI, A.C. ; POTENZA, M.R. Ácaros predadores em pomar cítrico de Presidente Prudente. Anais da Sociedade Entomológica do Brasil, v.23, n.3, p.435-441, 1994a.

SATO, M.E.; CERÁVOLO, L.C.; CEZÁRIO, A.C.; RAGA, A.; MONTES, S.M.N.M. Toxicidade residual de acaricidas a Euseius citrifolius Denmark \& Muma, 1970 (Acari: Phytoseiidae) em citros. Revista de Agricultura, v.69, n.3, p.257-267, 1994b.

SATO, M.E.; CERÁVOLO, L.C.; ROSSI, A.C.; CEZÁRIO, A.C.; POTENZA, M.R.; RAGA, A. Avaliação do efeito de acaricidas sobre ácaros-predadores (Phytoseiidae) e outros artrópodos em citros. Revista de Agricultura, v.70, n.1, p.57-69, 1995.

SATO, M.E.; CERÁVOLO, L.C.; ROSSI, A.C.; RAGA, A.; SOUZA FILHO, M.F. de. Toxicidade residual de acaricidas a Iphiseiodes zuluagai Denmark \& Muma, 1972 (Acari: Phytoseiidae). Arquivos do Instituto Biológico, São Paulo, v.63, n.1, p. 15-19, 1996.

SATO, M.E.; PASSEROTTI, C.M.; TAKEMATSU, A.P.; SOUZA FILHO, M.F. de; POTENZA, M.R.; SIVIERI, A.P. Resistência de Tetranychus urticae (Koch, 1836) a acaricidas, em pessegueiro (Prunus persica (L.) Batsch) em Paranapanema e Jundiaí, SP. Arquivos do Instituto Biológico, São Paulo, v.67, n.2, p.117-123, 2000.
SATO, M.E.; RAGA, A.; CERÁVOLO, L.C.; SOUZA FILHO, M.F. DE; ROSSI, A.C.; MORAES, G.J. de. Effect of insecticides and fungicides on the interaction between members of the mite families Phytoseiidae and Stigmaeidae on citrus. Experimental and Applied Acarology, v.25, p.809-818, 2001

SILVA, M.Z. da Interações intraguilda e toxicidade de agrotóxicos a Neoseiulus californicus (McGregor) e Agistemus brasiliensis Matioli, Ueckermann \& Oliveira no controle de Brevipalpus phoenicis (Geijskes) em citros. 2009. 120p. Tese (Doutorado em Agronomia, Área de Entomologia Agrícola) - Faculdade de Ciências Agrárias e Veterinárias - Universidade Estadual Paulista, Jaboticabal, 2009.

SILVA, M.Z. da OLIVEIRA, C.A.L. de; SATO, M.E. Seletividade de produtos fitossanitários sobre o ácaro predador Agistemus brasiliensis Matioli, Ueckermann \& Oliveira (Acari: Stigmaeidae). Revista Brasileira de Fruticultura, v.31, p.388-396, 2009.

VAN POTTELBERGE, S.; KHAJEHALI, J.; VAN LEEUWEN, T.; TIRRY, L. Effects of spirodiclofen on reproduction in a susceptible and resistant strain of Tetranychus urticae (Acari: Tetranychidae). Experimental and Applied Acarology, v.47, p.301-309, 2009.

YAMAMOTO, P.T.; PINTO, R.A.; PAIVA, P.E.B.; GRAVENA, S. Seletividade de acaricidas a inimigos naturais em citros. In: OLIVEIRA, C.A.L. de; DONADIO, L.C. (Ed.). Leprose dos citros. Jaboticabal: FUNEP, 1995. p.159-170.

YAMAMOTO, P.T.; BESSANEZI, R.B. Seletividade de produtos fitossanitários aos inimigos naturais de pragas dos citros. Laranja, v.24, n.2, p.353-382, 2003.

Recebido em $17 / 5 / 10$

Aceito em 17/11/11 